\section{Thieves of the state - a response}

To the Editor: 'Thieves of the state' - what a marvellous turn of phrase, damning and straight to the point. Dr Goldstein must be commended on her excellent letter. ${ }^{1}$ She has done what so many of us, her colleagues, have not had the courage or energy to do: stick out our necks and expose this shameful blot on South Africa's medical landscape.

Our citizens, whether they are the poor or those who pay the taxes, should be shown exactly how they are being screwed. Managementlevel public hospital consultants (principal specialists, in pre-OSD terms) receive a package in excess of a million rand annually, with full benefits, including a lifelong pension after 10 years' 'service'. Yet these and other 'full-timers' do unlimited private practice simultaneously. They are so conspicuous by their absence: late or non-attenders at meetings, never respond to emails, unavailable for outreach - what specialist with sick private patients wants to leave town for the day?

The example they set to their juniors is followed. Surprise, surprise, the next generation of specialists qualifies and does the same thing: gets a full-time consultant post and opens a private practice. Their peers, both genuine full-timers in the public service and specialists in private practice, despise them and are bitter about the situation.

Everyone knows about it, but no one blows the whistle. This is the most ominous aspect of all. In our province RWOPS (remunerative work outside the public service) was precipitately banned. This is unrealistic, as some RWOPS is entirely justifiable and advantageous to the state (research, additional teaching, etc.). Private practice, not RWOPS, should have been forbidden; alternatively, the limited private practice facility previously allowed should have been strictly monitored and enforced. Instead, there is less than lip-service to a non-existent embargo.

What is going on here? Is there a double or hidden agenda? Is there collusion? This is big-bucks business: are there backhanders, is money changing hands? Is it dangerous? Could a whistle-blower stop a bullet, never mind lose a job?

The health system would fall apart if they were to leave. I doubt it: the benefits and security of salaried employment have much to commend them. Put it to the test. Issue an ultimatum: stop private practice in 3 months or resign from the full-time post now. Go further. These are criminals. Stick a couple of them in jail. That would stop the rot overnight. Am I being harsh or over-dramatic? I know a couple of lawyers who have gone to prison for embezzlement of trust funds. Are we not looking at heinous betrayals of similar culpability?

It would be interesting to know the take of the national and provincial ministers of health on the matter. There is no problem in identifying the perpetrators. They have consulting rooms with phone numbers in the directory. One can make appointments.

Thieves of the state. Yes indeed. These are not derring-do catburglars or romantic Robin Hoods. These are the hoods who rob the poor to satisfy their greed. Nail them.

\section{Robert Ian Caldwell \\ Hilton, KwaZulu-Natal}

ric@caldwells.co.za

1. Goldstein LN. Thieves of the state. S Afr Med J 2012;102(9):719. DOI:10.7196/SAMJ.616

\section{Intimate partner violence}

To the Editor: I would like to make some comments on the issue of domestic violence. ${ }^{1}$ My understanding of this problem is that it is primarily a social problem that can lead to ill-health risks (physical, mental, emotional and even spiritual) and that it has three components: the perpetrator, the effect on women, and the effect on children.

Gass et al. ${ }^{2}$ addressed the impact of domestic violence on women. Their study exposes the size of the problem nationally, but does little to enlighten us about the ethnicity and socio-economic strata of the women involved. A community-based research workshop in Cape $\mathrm{Town}^{3}$ addressed issues around recognition and intervention from medical and legal perspectives. The facilitators were a social worker (Rebecca Rees) and a lawyer (Peter Volmink), with participation by doctors, nurses, social workers, childcare workers, church representatives and lay community members (izakha muzi). They discussed pitfalls in applying the Prevention of Domestic Violence Act and how to rectify these. Roleplay by women participants from the townships of Guguletu, kwaLanga and Mitchell's Plain revealed how domestic violence can be covered up when women seek healthcare for their physical injuries. The multi-disciplinary training espoused by Gass et al. ${ }^{2}$ could help family doctors to improve screening and detection of domestic violence in women who present in primary care.

We also need to guard against 'medicalising' this problem by focusing mainly on the physical effects. I see the medical role in diagnosing bruises, fractures, etc. - an area of family medicine where research is still needed to distinguish between accidental and nonaccidental injuries.

Further discussions and research on domestic violence must not only address women but also focus on the male gender and paediatric factors. More focus on children as victims of domestic violence, on the risk factors for such abuse, and the knowledge and skills to recognise signs and symptoms of child abuse, ${ }^{4}$ are also needed.

\section{E M Mankazana}

General practitioner

London, UK

mxomank@doctors.net.uk

1. Bateman C. SA men - time for introspection/renewed action? S Afr Med J 2012;7:597-598

Gass JD, Stein DI, Williams DR, Seedat S. Intimate partner violence, health behaviours and chronic illness among South African women S Afr Med J 2010;100:582-586.

3. Mankazana EM. From Exile to Exile. New York: Authorhouse, 2011.
4. The Scottish Government. National Guidance for Child Protection in Scotland 2010. www.scotland. gov.uk/Resource/Doc/334290/0109279.pdf (accessed 8 August 2012).

S Afr Med J 2012;102(10):775. DOI:10.7196/SAMJ.6207

\title{
Correction
}

We regret an omission in the February 2012 printed SAMJ, in the article by Lowman et al. entitled 'Comparative MIC evaluation of a generic ceftriaxone by broth microdilution on clinically relevant isolates from an academic hospital complex in South Africa. Table I was inadvertently omitted; it was subsequently included in the online article, as p. 103a, on 22 June 2012. 